By IAN W. THOM

\title{
The Divided Catalog in College and University Libraries
}

$M r$. Thom is general assistant, processing division, Harvard College Library.

$\mathrm{F}^{\mathrm{OR}}$ some time librarians have been con$\mathrm{F}_{\text {cerned over certain alleged shortcomings }}$ of the dictionary catalog, concentrating much of their attention on its increasing bulk and complexity. Proposals for reform have been suggested. These range all the way from pleas for simpler filing to the possible abolition of the card catalog itself. One scheme, that of splitting the single catalog into separate author, title and subject files, has received considerable attention and has actually been put into effect during the past decade by a number of important academic libraries.

Many administrators are looking at these experiments in division with curiosity, but there is little to guide the librarian who is trying to decide whether or not to divide his own catalog. Since 1938, II papers of varying importance have appeared, most of them of necessity limited in scope and subjective in their discussion of the advantages claimed and the problems involved. ${ }^{1}$ The

1 Wood, Amy F. "California Divides Its Catalogue." Library fournal 63: 723-26, Oct. $1,1938$.

McAnally, Arthur M. "Library and the Card Cata$\log$." Library Journal 63: 814-15, Nov. 1, 1938.

Allez, George C. "In Defense of the Alphabetical Subject Catalog." Wilson Bulletin $\mathrm{r}_{3}: 242-43$, December 1938 .

Hagedorn, Rolf. "Toward Catalog Reform." Library

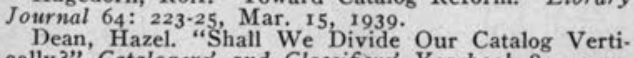
cally?" Catalogers' and Classifiers' Yearbook 8: 43-47, 1939.

Lubetzky, Seymour. "Crisis in the Catalog." Cata-

logers' and Classifiers' Yearbook 8: 48-54, 1939.

Wood, Amy F. "The Large Dictionary Catalog Faces

Der Tag." Catalogers" and Classifiers' Yearbook 8: 39.

${ }^{42}$. 1939 .

"Crisis in Cards." Dartmouth College Library. Lirary Bulletin 3: ${ }^{1} 5 \mathrm{x}-54$, December ${ }^{1} 94 \mathrm{I}$,

Burch, Vella J. "Divided Catalog; Duke University Library Faces the Future." College and Research Li. braries 3:219-23, June 1942 . most recent article, however, presents an example of the type of study hitherto lacking. It is the report of an investigation, conducted by Amy Wood Nyholm at the University of California in 1944, of readers' reactions to the divided catalog. Although it does not answer all questions about the divided catalog, it provides some new data on the problem of the users' approach.

The present study was designed to contribute toward the objective appraisal of the division of the catalog. It concentrated upon certain aspects of the problem relating primarily to administration. The following questions, posed at the beginning of the project, reveal the general trend of the investigation:

I. What percentage of academic libraries have divided their catalogs?

2. What were their reasons for doing so?

3. Has division justified the hopes of its advocates?

4. Have any libraries abandoned division in favor of a return to the single file? If so, why?

5. To hat extent is it necessary to duplicate entries, and what kinds of entries are most frequently duplicated?

6. What is the effect on the physical bulk of the catalog?

7. What is the effect on cataloging costs?

8. Does division facilitate the work of the staffs concerned?

For practicability, the field was limited to member institutions of the Association

Adams, Winona. "Divided Catalog in Practice." PNLA Quarterly 7: 48-50, October 1942.

Nyholm, Amy Wood. "California Examines Its Divided Catalog." College and Research Libraries 9: r95.201, July 1948. 
of American Colleges, and to colleges and universities approved by the Association of American Universities. In all, 642 libraries were canvassed. The inquiry was concerned solely with the main public catalog on each campus.

A questionnaire was drawn up with considerable help from interested and very cooperative librarians. Before making use of it, however, an explanatory post card with return card attached was sent to each of the 642 libraries to discover which of them had the divided catalog. The card also inquired about willingness to cooperate in the project.

\section{Prevalence}

Answers to this preliminary inquiry were obtained from 457 institutions, 24 of which had divided their catalogs. Questionnaires were then sent out, and these were completed in whole or in part by 23 librarians. The divided catalogs were found in 20 states. The greatest concentration in proportion to the number of institutions was in the Far West, where II.I per cent of the libraries queried have adopted division.

The earliest instance of division occurred in 1928 when a new college in the Far West organized its library with a divided catalog. From 1928 to 1937 there existed but three divided catalogs among the group studied, but in the following decade, 1938 to 1947 , 20 more catalogs were divided. The frequency curve representing the cumulative increase in the number of divided catalogs rises sharply from 1938 to $194 \mathrm{I}$, at which point the ascent becomes less abrupt. In 1944, when three catalogs were divided, the curve starts up again and then climbs moderately but steadily. The slight hesitation in the line just after I94I perhaps reflects the unsettling conditions resulting from America's entry into the war. That the trend toward division is still alive is evidenced by the fact that although the preliminary post card did not inquire about future plans, thirteen respondents volunteered the information that they were "considering" division.

The collections covered by the divided catalogs range in size from 33,000 to 1,300,000 volumes. The percentage of such catalogs increases sharply as the size brackets climb. This was brought out by dividing the 642 libraries queried into three arbitrary size groups: small, medium and large. The summary below shows the percentage of libraries with the divided cata$\log$ within each category:

\begin{tabular}{|c|c|c|}
\hline $\begin{array}{l}\text { Library Size } \\
\text { (Volumes) }\end{array}$ & $\begin{array}{l}\text { Number of } \\
\text { Libraries } \\
\text { Queried }\end{array}$ & $\begin{array}{c}\text { Percentage of } \\
\text { Libraries with } \\
\text { Divided } \\
\text { Catalog }\end{array}$ \\
\hline Under 100,000 & 482 & I. 6 \\
\hline 100,000 tc & 131 & 8.3 \\
\hline Over 499,000 & 29 & 17.2 \\
\hline
\end{tabular}

The arrangement whereby author and title entries are housed in one section and subject entries in another prevails throughout. Only one library, a very small one, was found to have tried division ( 1934 to 1937) and then to have changed back to the single arrangement. In this instance the three file system (author, subject and title) was in effect during the period of division. The dictionary catalog was restored because of the confusion caused by the need for looking in three different places for information. Some people did not understand the difference between subjects and titles, and between authors and names as subjects.

\section{Reasons for Division}

Sixteen specific "reasons for division" were submitted to the respondents who were asked to check the items that applied to their respective libraries and to rank them in order of importance. Twenty librarians ranked their responses while two merely listed them. One of the latter also 
indicated that the reasons checked by him were "probable reasons."

Difficulties connected with complex or illogical filing constitute the leading reason for division. Eighteen of the 22 respondents reported that their students were confused by filing complexities, and 14 claimed that even patrons familiar with the rules wasted too much time. Nine mentioned filing errors, and seven the excessive amount of time consumed in filing. Ten librarians gave some item within this category top rank among their reasons for dividing.

The type of filing code in use before and after division is of considerable interest in this connection. In the process of splitting their catalogs, at least I I libraries adopted a more strictly alphabetical filing scheme than they had used previously.

The relieving of congestion at the cata$\log$ cabinets was second among the reasons for division, but it was by no means a close rival to filing difficulties. Although mentioned by 15 librarians, it was given first place by only three, while many relegated it to third or fourth place. The "congestion" referred to results from the conflict between those who merely wish to obtain call numbers or to find out if the library has specific authors and titles, and those who wish to study subject cards at some length.

The alleged need to vitalize the subject approach to library materials was in no instance the primary reason for division but I I librarians had the idea in mind when drawing up their plans. It was evidently believed that subject cataloging was not yielding results proportionate to its expense. This particular key to a library's collection was not fully utilized by the students because it was buried, so to speak, among the other types of entries.

Problems of space and physical layout ranked fourth among the reasons for division. This category scored only slightly lower than did the previous reason. Nine libraries had such problems, and three resorted to division primarily to solve them. In the words of one respondent: "Our catalog was full and could not be enlarged. Therefore we withdrew the subject cards and set up a new catalog about 25 feet from the author-title catalog."

Another library, apparently not having room for its entire catalog along the wall of the delivery hall, has placed its subject cards in the reference room on the other side of that wall. There is easy access between the two files.

It is not unusual for catalogs to outgrow their original places and to begin to creep along walls and into adjacent rooms. However, when a catalog is divided for this reason it is usually divided at some point along the alphabetical sequence of the entries, rather than according to the function of the entries. One may wonder, other considerations aside, why the latter type of division should be considered superior to the former. In both cases, the user must walk back and forth between the two sections. The claim has been put forward by at least one advocate of functional division that the reader works considerably more within the author-title grouping, and within the subject grouping, than back and forth between them.

That "other libraries were obtaining good results from division" was stated by eight libraries to have been a factor in influencing them to divide. No less than four respondents gave this reason first rank, but in the final scoring it stood only fifth.

The category of reasons relating to the promotion of staff efficiency did not score very heavily. Eight libraries named one or more of the reasons within this group, but none gave any of them first place. The statement "reference department desired separate subject file for facilitation of its work" was checked on five returns. Four 
libraries believed that a separate author (or author-title) file would benefit the catalogers, and an equal number believed that such a file would aid the acquisitions librarians. However, the low score obtained by this category would seem to indicate that division was planned primarily with the students and not the staff members in mind. It might also be inferred that the librarians for the most part did not find the dictionary arrangement a handicap in their work.

Student apprehension at the sheer size of the catalog (quite apart from confusion at internal complexities) is a subjective and elusive factor. However four librarians named süch apprehension as a reason for dividing, and one of them gave it first place.

\section{Attainment of Objectives}

The questionnaire embodied a rating scale for the purpose of obtaining staff opinion on the divided catalog in use. Twelve objectives of division were listed, and for each, the repondents were asked to check one of the following degrees of attainment: "matters made worse," "no improvement," "a slight improvement," "a marked improvement," "a very great improvement."

Slightly over 43 per cent of the 23 respondents claimed that division has relieved student confusion at filing complexities to a "marked" degree, and none claimed a "very great" improvement in this respect. Seven librarians, or 30.4 per cent, reported a "slight" gain, one saw no improvement, and another believed that matters have been made worse. The "not applicable" column was checked by one respondent, but for this item such a response can be equated with "no improvement," for if there had been a gain to report it is difficult to think that it would not have been mentioned. Three librarians did not answer this question. Of the 18 libraries that had specifi- cally aimed for this objective, nine claimed that it had been attained to a "marked" degree.

Slightly over half of the respondents claimed that finding has been facilitated to a "marked" or to a "very great" degree for those familiar with catalogs. Of the 14 libraries that had the relief of this class of patrons in mind when dividing, nine reported a "marked" improvement or better. Filing errors were reduced to "marked" degree or better in 60.8 per cent of the libraries, and 56.4 per cent claimed a similar degree of success in reducing filing time. Two large libraries, however, reported that filing time has increased. Seven of the nine libraries that had divided in part to reduce filing errors, and every one of the seven that had done the same to reduce filing time, reported in the two most favorable columns.

Twelve, or 52.1 per cent of the libraries, found that congestion has been relieved to a "marked" extent, and one library reported a "very great" improvement. Of the I5 libraries that had mentioned congestion as a reason for dividing, II claimed that relief has been attained to a "marked" degree or better. In regard to the emphasizing of the subject approach, one librarian saw no improvement, six reported a "slight," twelve a "marked," and one a "very great" improvement. Seven of the Io institutions that had consciously aimed in this direction reported either "marked" or "very great" progress.

Division does not seem to have facilitated reference work to any great extent, for Io libraries reported a "slight" improvement in this matter, five claimed a "marked" improvement, and one claimed a "very great" advance. One respondent held that the situation has deteriorated, and two checked the "no improvement" column. Seven librarians thought that division had facilitated the work of the catalogers to a 
"marked" degree, while two reported in the "very great" improvement column. Two others, however, indicated that matters have been made worse. Division seems to have been more successful in facilitating acquisitions work than in attaining any of its other objectives. Fifteen libraries reported in the two highest columns, while of the four institutions that had deliberately sought to increase efficiency in area of activity, three claimed a "very great" improvement.

Of the four libraries that had divided, partly because the sheer outward size of the catalog created apprehension in the minds of many students, only one reported that division has brought about as much as a "marked" diminution of such apprehension. Three libraries had divided partly because of the absence of an official catalog, but only one of these thought that the change rated even as high as a check in the "slight improvement" column. The one library that had hoped its subject file would serve as a compromise between the dictionary and the classed arrangement, reported "great success" in this matter.

Seven libraries were found to be no longer under the administrators who had been responsible for the division of their respective catalogs. However this fact had no significant effect on the attainment ratings submitted by these institutions.

\section{Duplication of Entries}

A list of 18 types of works thought most likely to call for extra entries was submitted to the respondents who were asked to indicate their policy with regard to each of them. Practice varies widely; no clear cut norm stands out. Of 2 I libraries, three do no duplication at all while one duplicates for 15 types of works. Ten libraries, a bare majority, make duplicate entries for between two and five classes of works.

Two-thirds of the libraries make extra cards for autobiography and for works formerly requiring no title entry because of the coincidence between subject and title. The percentages of libraries making extra cards for the other main classes are as follows: works where catchword title formerly served as subject, 42.8 per cent; art books where the artist is regarded as author, 38 per cent; letters, 33.3 per cent; biography of authors, 28.5 per cent; laws, statutes, 19 per cent; "autobiographical" publications of governments, societies and institutions, I9 per cent; critical works and commentaries, I 9 per cent. "Autobiographi. cal" publications of such organizations as scientific expeditions, ships, firms, exhibitions and presses are given duplicate entries by only one, two, or three libraries.

It is interesting to note that four libraries make extra cards for critical works on personal authors. This class of literature probably bulks as large as that of biography of authors in the type of library under consideration. The same four libraries (all heavy duplicators) make extra cards for the latter category as well. Such extensive duplication cannot but have some perceptible effect on the bulk of the files and on cataloging costs. It is not surprising that two of these libraries contributed such remarks as: "probably do some duplication that is not really needed," "duplication is expensive," and "may discontinue duplication of cards."

Seventeen libraries also duplicate cross references when the corresponding entries are duplicated. Concerning this undertaking, one of the respondents quoted just above adds: "This could not be done thoroughly because of the great expense."

No relationship was discovered between the degree of success claimed and the amount of duplication done. College A, which reportedly attained all 12 objectives of division to a "marked" degree or better, does no duplication whatever, while college $\mathrm{U}$, whose librarian could not say that divi- 
sion has been as much as a "marked" success in any respect, also refrains from duplication. One institution which duplicates in three instances recorded seven objectives attained to a "marked" degree or better while another library which does the same amount of duplication believes that only one goal has been attained to this extent. The library which does most duplication reported four "marked" or better successes, while another library making similar claims, duplicates for only one type of work.

The respondents were asked to estimate the per cent of increase in the number of title cards, and the per cent of increase in cards of all types. The response was unsatisfactory; only a handful of librarians essayed such estimates. On the basis of these fragmentary replies it would appear that an "average" policy of duplication would increase the number of title cards by between five and 25 per cent, and the total number of cards by about five per cent.

\section{Concluding Remarks}

On the whole, the divided catalog has been found a more effective tool than the single catalog, but its superiority does not appear to be outstanding. The attainment rating scale registered a hearier vote in the combined "matters made worse" and "no improvement" columns than in the "very great improvement" column. And in the two most favorable columns, some of the more important objectives failed to score as highly as did certain lesser ones. Simplicity for the student was the great objective, but apparently not the great success of division. Perhaps a psychological "main entry" bias was an inhibiting factor in limiting all the catalogs studied to the invariable author-title and subject duality, and in precluding the exploration of other possibilities.

It is suggested that every effort be made to increase the effectiveness of the dictionary catalog before resorting to division. If the latter course is decided upon, a division into a name file, a title file, and a topical subject file might well be tried. Lubetzky, in his contribution to the subject, advocates this scheme. ${ }^{2}$ Such an arrangement carries simplification further than does the usual type of division, and renders duplication unnecessary.

$2 O p$. cit.

\section{News Notes on Library Buildings}

Librarians now in the process of planning a new building might well make certain that their architects examine an article found in the June issue of Standardization, the news magazine of the American Standards Association. This issue contains an article by George L. Diggles describing the attempts of the American Standards Association to standardize some 25 sizes of fluorescent lamps. At the present time the Association has grouped these
25 sizes into five general types. Apparently bulbs which are developed for each of these five types will not fit fixtures for the other four types.

The problem reported by these standards is not one that will trouble librarians directly, but it is one that our architects will want to know about. Most architects, of course, follow closely the work of the American Standards Association.-R. E. Ellsworth. 